\title{
Percutaneous Flexible Peritoneoscopy for Evaluation of Indeterminate Ascites
}

\author{
Nikhil Bush ${ }^{1}$ Jayendra Shukla ${ }^{1}$ Surinder S. Rana ${ }^{1}$ \\ ${ }^{1}$ Department of Gastroenterology, Postgraduate Institute of \\ Medical Education and Research (PGIMER), Chandigarh, India \\ ${ }^{2}$ Department of Surgical Gastroenterology, Postgraduate Institute \\ of Medical Education and Research (PGIMER), Chandigarh, India
}

J Digest Endosc 2021;12:167-168.

A 46-year-old male patient was a known case of alcohol-related chronic pancreatitis with underlying chronic liver disease. He presented with fever and abdominal distension. With suspicion of spontaneous bacterial peritonitis, an ascitic fluid examination was done, which showed leukocytosis $\left(49,491\right.$ cells $\left./ \mu \mathrm{m}^{3}\right)$, high protein $(2.9 \mathrm{~g} / \mathrm{dl})$ and low glucose $(5 \mathrm{mg} / \mathrm{dl})$ levels. It was lymphocyte predominant with elevated adenosine deaminase levels (46 U/1), and culture had growth of Staphylococcus aureus, for which patient was started on sensitivity-based antibiotics. In view of persisting sepsis, ascites was drained using two $14 \mathrm{Fr}$ percutaneous drain catheter placed in bilateral flanks (-Fig. 1). Despite intravenous antibiotics and drainage, the fever persisted. 18-FDG positron emission tomography (PET) revealed nonuniform peritoneal uptake. A PET-guided fine needle aspiration from peritoneal lesions was inconclusive. No peritoneal deposits were visualized on endoscopic ultrasound (EUS). With no definite etiology of ascites, we decided to do a flexible peritoneoscopy under conscious sedation. The previously placed drain was removed over a guidewire, and a 5.8-mm ultrathin endoscope was inserted into the peritoneum over the guidewire along the catheter tract (Video 1). Carbon dioxide was used for insufflation. The visceral peritoneum was observed to be inflamed and friable with fibrinous exudate ( $\mathbf{- F i g}$. 2). No peritoneal deposits were observed, and the peritoneal cavity was flushed and cleaned with saline. Antibiotics were continued and the patient gradually improved. The drains were subsequently removed, and patient is doing well on follow-up without recurrence of ascites or fever.

\author{
Rajesh Gupta²
}

Address for correspondence Surinder S. Rana, MD, DM, FASGE, Department of Gastroenterology, Postgraduate Institute of Medical Education and Research (PGIMER), Chandigarh 160012, India (e-mail: drsurinderrana@gmail.com).

\section{Video 1}

Peritoneum being visualized using a 5.8-mm ultrathin endoscope after insertion into the peritoneal cavity along the percutaneous catheter tract.

Patients with inconclusive ascitic fluid analysis are a diagnostic dilemma that usually requires laparoscopy to solve the diagnostic conundrum. EUS is an excellent modality for diagnosing and sampling small peritoneal deposits in patients with undiagnosed ascites. ${ }^{1}$ Percutaneous ultrathin flexible peritoneoscopy also seems to be technically feasible method for evaluation of peritoneum in patients with undiagnosed ascites. ${ }^{2}$ The advantage of this approach is that the peritoneal cavity can be examined under conscious sedation, and no suturing is required to close the abdominal wall defect. Also, the abnormal peritoneal lesions can be biopsied under endoscopic vision for establishing a diagnosis. However, carbon dioxide should be used for insufflation to reduce the risk of embolism. Moreover, use of carbon dioxide is associated with minimal postprocedure discomfort because of rapid absorption across the membranes and excretion via the lungs. A detailed anatomical knowledge of the peritoneal cavity is required to perform this procedure successfully. Also, this procedure can be performed only in the presence of ascites. Despite the advantages of carbon dioxide for insufflation, it should be used sparingly because large volumes of carbon dioxide can get absorbed into the circulation, causing a high $\mathrm{pCO}_{2}$ and a low $\mathrm{pH}$ with its clinical consequences, including
DOI https://doi.org/ $10.1055 / \mathrm{s}-0041-1739972$ ISSN 0976-5042 (c) 2021. Society of Gastrointestinal Endoscopy of India.

This is an open access article published by Thieme under the terms of the Creative Commons Attribution-NonDerivative-NonCommercial-License, permitting copying and reproduction so long as the original work is given appropriate credit. Contents may not be used for commercial purposes, or adapted, remixed, transformed or built upon. (https://creativecommons.org/licenses/by-nc-nd/4.0/). Thieme Medical and Scientific Publishers Pvt. Ltd. A-12, 2nd Floor, Sector 2, Noida-201301 UP, India 


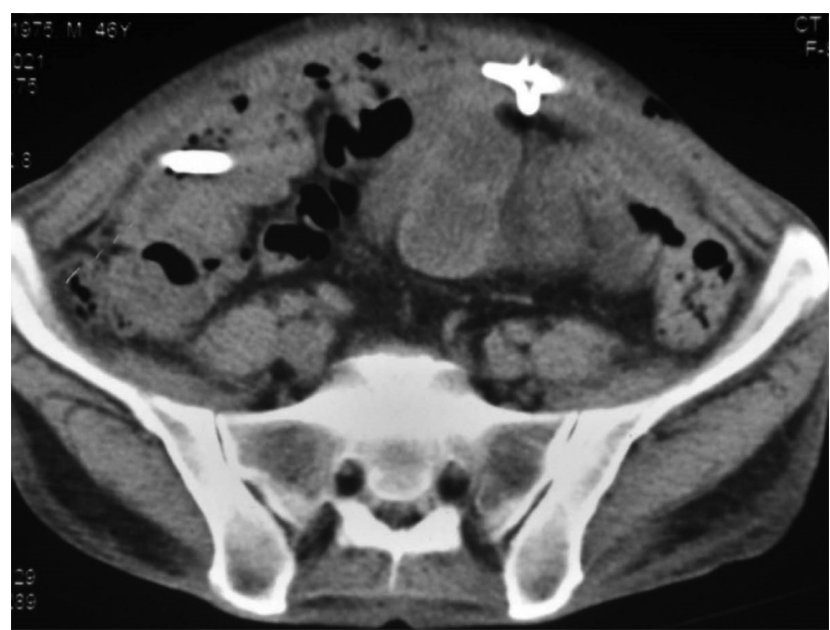

Fig. 1 CT abdomen: infected ascites drained with bilateral flank percutaneous drains.

lowering of the arrhythmia threshold, increased blood pressure, pulse and cardiac output. ${ }^{3}$

\section{Author Contributions}

1. N.B.: Drafting of manuscript, collection of data.

2. J.S.: Drafting of manuscript, collection of data.

3. S.S.R.: Critical evaluation of manuscript, collection of data.

4. R.G.: Collection of data.

\section{Funding}

No funding.

\section{Conflict of Interest}

None declared.

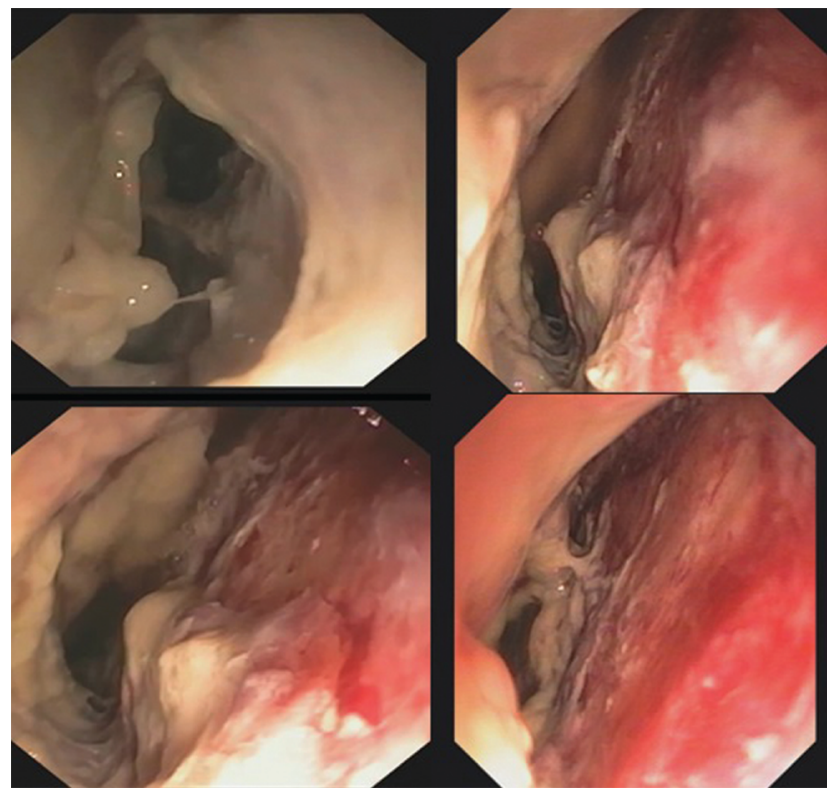

Fig. 2 Flexible peritoneoscopy shows inflamed peritoneum with fibrinous exudates.

\section{References}

1 Rana SS, Bhasin DK, Srinivasan R, Singh K. Endoscopic ultrasound-guided fine needle aspiration of peritoneal nodules in patients with ascites of unknown cause. Endoscopy 2011;43(11):1010-1013

2 Kim MS, Kwon HY, Bang BW, et al. Percutanous ultrathin flexible peritoneoscopy for detecting peritoneal metastasis: a feasibility study. Korean J Helicobacter Up Gastrointest Res 2013;13:167-172

3 Naude GP, Bongard FS. Helium insufflation in laparoscopic surgery. Endosc Surg Allied Technol 1995;3(4):183-186 